\title{
Kegelräder und Kegelradgetriebe
}

TB 22-1 Richtwerte zur Vorwahl der Abmessungen (Kegelräder)

\begin{tabular}{|c|c|c|c|c|c|c|c|c|c|}
\hline $\begin{array}{l}\text { Übersetzung } i \\
\text { Zähnezahlverhältnis } u\end{array}$ & 1 & 1,25 & 1,6 & 2 & 2,5 & 3,2 & 4 & 5 & 6 \\
\hline Zähnezahl des Ritzels $z_{1}$ & $40 \ldots 18$ & $36 \ldots 17$ & $34 \ldots 16$ & $30 \ldots 15$ & $26 \ldots 13$ & $23 \ldots 12$ & $18 \ldots 10$ & $14 \ldots 8$ & $11 \ldots 7$ \\
\hline $\begin{array}{l}\text { Breitenverhältnis } \\
\psi_{\mathrm{d}}=\frac{b}{d_{\mathrm{m} 1}}\end{array}$ & 0,21 & 0,24 & 0,28 & 0,34 & 0,4 & 0,5 & 0,6 & 0,76 & 0,9 \\
\hline
\end{tabular}

TB 22-2 Werte zur Ermittlung des Dynamikfaktors $K_{\mathrm{v}}$ für Kegelräder (nach DIN 3991-1)

a) für Geradverzahnung; b) für Schrägverzahnung

\begin{tabular}{|c|c|c|c|c|c|c|c|}
\hline Qualität & 6 & 7 & 8 & 9 & 10 & 11 & 12 \\
\hline$K_{1}$ & 9,5 & 15,34 & 27,02 & 58,43 & 106,64 & 146,08 & 219,12 \\
\hline $\begin{array}{ll}K_{2} & \text { a) } \\
& \text { b) }\end{array}$ & & & & $\begin{array}{l}1,0645 \\
1,0000\end{array}$ & & & \\
\hline $\begin{array}{ll}K_{3} & \text { a) } \\
& \text { b) }\end{array}$ & & & & $\begin{array}{l}0,0193 \\
0,0100\end{array}$ & & & \\
\hline
\end{tabular}

TB 22-3 Überdeckungsfaktor (Zahnfuß) $Y_{\varepsilon}$ für $\alpha_{n}=20^{\circ}$ (nach DIN 3991-3)

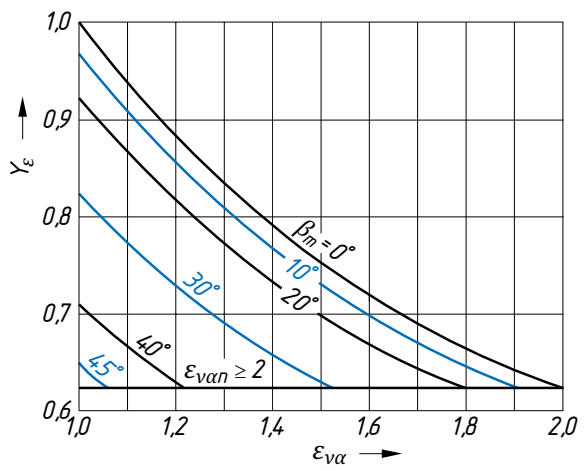

(C) Der/die Herausgeber bzw. der/die Autor(en), exklusiv lizenziert durch Springer Fachmedien Wiesbaden $\mathrm{GmbH}$, ein Teil von Springer Nature 2021

H. Wittel, C. Spura, D. Jannasch, Roloff/Matek Maschinenelemente Band 2,

https://doi.org/10.1007/978-3-658-34160-2_46 